\title{
A tool for the in vivo gating of gene expression in neurons using the co-occurrence of neural activity and light
}

\author{
Adam T. Vogel ${ }^{* 1,2}$ and Shelley J. Russek ${ }^{1,2,3,4}$
}

1) Graduate Program for Neuroscience, Boston University; 2) Center for Systems Neuroscience, Boston University, Boston, Massachusetts, U.S.A; 3) Departments of Pharmacology \& Experimental Therapeutics, and Biology, Boston University, Boston, Massachusetts, U.S.A.; 4) Laboratory of Translational Epilepsy, Boston University School of Medicine, U.S.A.

Running Title: Genetic expression system for coincidence detection of light and intranuclear calcium

*Corresponding Author: Adam T. Vogel

Email: atvogel@bu.edu

Number of text pages: XX

Number of figures: 3

Acknowledgements:

We would like to acknowledge the mentorship and support of the Michael Hasselmo laboratory during the course of this technology development and the members of the Russek and Hasselmo laboratories, with especial thanks to Sabita Bandyopadhyay, Zhuting Li, and Kathryn Hixson. 
This work was supported by NINDS 5R01NS051710-14 and the BU Provost award for collaborative neuroscience research.

\begin{abstract}
Advancements in genetically based technologies have begun to allow us to better understand the relationships between underlying neural activity and the patterns of measurable behavior that can be reproducibly studied in the laboratory. As this field develops, there are key limitations to the currently available technologies hindering their full potential to deliver meaningful datasets. The limitations which are most critical to advancement of these technologies in behavioral neuroscience are: the temporal resolution at which physiological events can be windowed, the divergent molecular pathways in signal transduction that introduce ambiguity into the output of activity sensors, and the impractical size of the genetic material that requires 3-4 separate AAV vectors to deliver a fully functional system into a cell. To address these limitations and help bring the potential of these types of technologies into better realization, we have engineered a nucleus localized light-sensitive $\mathrm{Ca}^{2+}$-dependent gene expression system based on $\mathrm{AsLOV}_{2}$ and the downstream responsive element antagonist modulator (DREAM). The design and engineering of each component was performed in such a way to: 1) preserve behaviorally relevant temporal dynamics, 2) preserve signal fidelity appropriate for studying experiencedriven neural activity patterns and their relationship to specific animal responses, and 3) have full delivery of the genetic material via a single AAV vector. The system was tested in vitro and subsequently in vivo with neural activity induced by Channelrhodopsin and could be used in the future with behaviorally-driven neural activity. To our knowledge this is the first optogenetic tool for the practical use of linking activity-dependent gene activation in response to direct nuclear calcium transduction.
\end{abstract}




\section{Main}

Neuroscientists have been developing a wide range of new tools to study the patterns of neural activity underlying behavior. For example, advances in optics and intracellular calcium $\left(\mathrm{Ca}^{2+}\right)$ indicators have allowed for simultaneous stimulation and observation of individual neurons within animals ${ }^{1-3}$. In parallel, a wave of new genetically encoded tools has further advanced our ability to monitor and perturb neural activity ${ }^{4-8}$. Though these technological advancements are promising, they are limited in accessibility and application to the field of neuroscience as a whole. The cost, both in terms of finance and human resources, of new optical microscopic systems is a barrier that many labs are unable to overcome. A solution to this problem may lie in recently developed genetically engineered tools which do not require large optical configurations to modulate and interact with.

Genetic technologies have often relied on pharmacological agents for temporal specificity. Due to slow pharmacological dynamics and long half-life, the temporal resolution at which pharmacologically based tools can window activity-dependent gene transcription severely limits their use in behavioral research. Recently, tools have been developed to enable researchers to gate gene expression in neurons by dynamic changes in the concentrations of calcium $\left(\mathrm{Ca}^{2+}\right)$ within the cell bodies of individual neurons, known as cytosolic $\mathrm{Ca}^{2+9,10}$. While localized transduction of cytosolic $\mathrm{Ca}^{2+}$ can be used as a biomarker of long-term cellular changes in individual neurons, the inherent ambiguity of divergent cytosolic $\mathrm{Ca}^{2+}$-signaling pathways and their relationship to extracellular signaling greatly limits our ability to interpret the meaning behind them ${ }^{11-15}$. For example, it is unclear if a given $\mathrm{Ca}^{2+}$ signal is due to a subthreshold oscillation, a train of action potentials, or release of an intracellular $\mathrm{Ca}^{2+}$ store ${ }^{12,16-20}$. Additionally, these technologies are composed in large genetic encodings which greatly hinders 
their practical use in in vivo behavioral experiments. To be effective, such technologies will need to possess key characteristics including: (i) behaviorally relevant temporal dynamics of its gating mechanisms, (ii) minimal cross-reaction with other cellular molecules, and (iii) ease of use in a variety of organisms. We are particularly interested in detecting calcium signals that regulate activity-dependent gene expression important for learning and memory, as well as for the propagation of hyperactivity of neurons that occurs during epileptogenesis and neurodegeneration.

Several studies have shown nuclear $\mathrm{Ca}^{2+}$ transients evoked by experience-driven synaptic activity to be distinct events representing the propagation of information mediated by action potentials ${ }^{21-26}$. We set out to make a tool that would detect such $\mathrm{Ca}^{2+}$ transients using a genetic readout relevant to endogenous activity-dependent gene regulation. This tool, called CLiCK $\left(\mathrm{Ca}^{2+}\right.$ Light Coincidence $\left.\mathrm{Knock}_{\text {in/out}}\right)$, is a dual condition genetic expression system. In neurons, CLiCK acts as a coincidence detector for the co-occurrence of neural activity (as monitored by the presence of transient nuclear $\left.\mathrm{Ca}^{2+}\right)$ and blue light $(\sim 450 \mathrm{~nm})$. Transcription occurs only through the simultaneous release of both gating mechanisms. Neither light nor activity alone are sufficient to induce reporter gene expression. We demonstrate high temporal responsiveness of CLiCK in vivo, enabling subsecond windowing of behaviorally-driven neural activation, in contrast to pharmacological windows that last many hours. To eliminate failures due to incomplete delivery of transgenes using multiple viral vectors, we engineered the entirety of CLiCK into a single multicistronic unit $<2.5 \mathrm{~KB}$; small enough to deliver via a single AAV vector and containing a transcriptional marker (ZsGreen) for vector detection.

The photo-switch in CLiCK comes from the light-oxygen-voltage (LOV) sensitive domain from Avena sativa $\left(\mathrm{AsLOV}_{2}\right)^{27,28}$. The C-terminus of native $\mathrm{AsLOV}_{2}$ contains a photo- 
reactive J $\alpha$-helix domain. In the absence of light, the J $\alpha$-helix adducts into core $\beta$-sheets of the phototropin, burying several hydrophobic residues. Exposure to blue light induces core structural changes, originating at the flavin mononucleotide (FMN) binding pocket, which propagate to the C-terminus causing the J $\alpha$-helix to unfold, exposing its residues. The photo-driven abduction and thermal reversal of LOV domains establish photo-stationary equilibrium in the sub millisecond time scale ${ }^{29,30}$, well positioned to capture a behaviorally relevant event. In addition to thermal reversion, UV light can be used to drive LOV domains back to their adducted ground state at rates of picoseconds ${ }^{31}$.

To make the CLiCK transcription factor $\left(\mathrm{CLiCK}_{\mathrm{tf}}\right)$, we linked an NLS-Gal 4 DNA binding domain to the N-terminus of the phototropin $\mathrm{AsLOV}_{2}$ using a flexible GS-linker (to decrease the chances of functional interference between protein domains). Independent of light, $\mathrm{CLiCK}_{\mathrm{tf}}$ localizes to its specific DNA binding site, the upstream activator sequence (UAS), positioned upstream of the mRuby 2 transgene (Fig. 1a). A chimeric J $\alpha$-transactivator domain (AD) (see below for identification) was engineered into the C-terminus for light-switchable allosteric gating to attract co-activator proteins (Fig. 1b). In the dark state, catalytic residues of the AD are buried in the core "cage" of the protein. When exposed to blue light, conformational changes within the core sheets of the transcription factor propagate to the $\mathrm{C}$-terminus. This propagation leads to unfolding of the J $\alpha$-helix, subsequently exposing critical residues of $\mathrm{AD}$ that are recognized by transcriptional cofactors necessary to drive transcription of mRuby2. 
bioRxiv preprint doi: https://doi.org/10.1101/2021.12.05.471336; this version posted December 7, 2021. The copyright holder for this preprint (which was not certified by peer review) is the author/funder, who has granted bioRxiv a license to display the preprint in perpetuity. It is made available under aCC-BY-ND 4.0 International license.

a
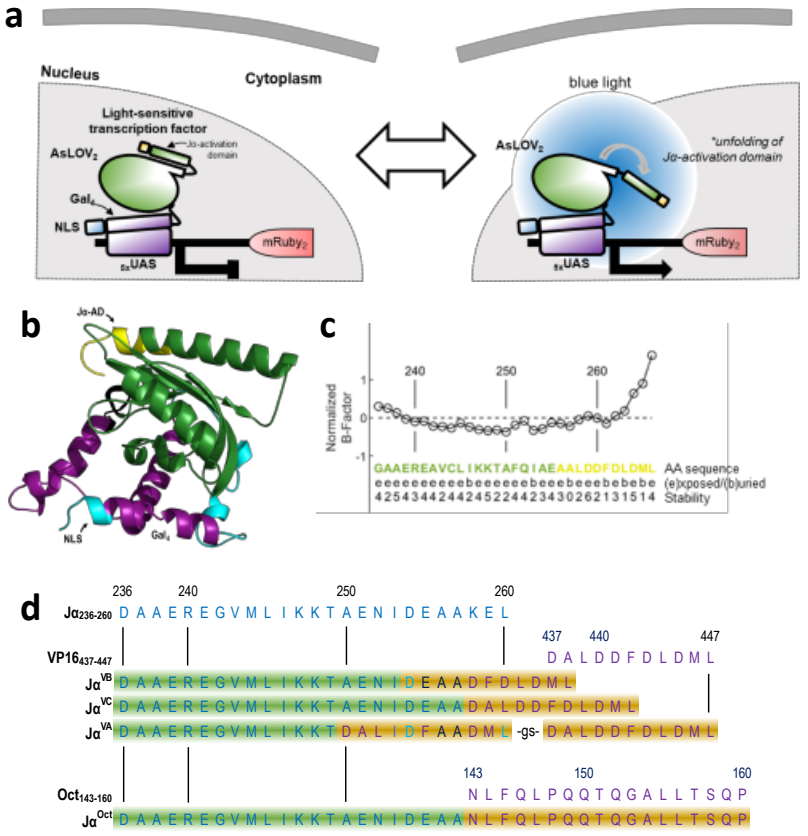

e

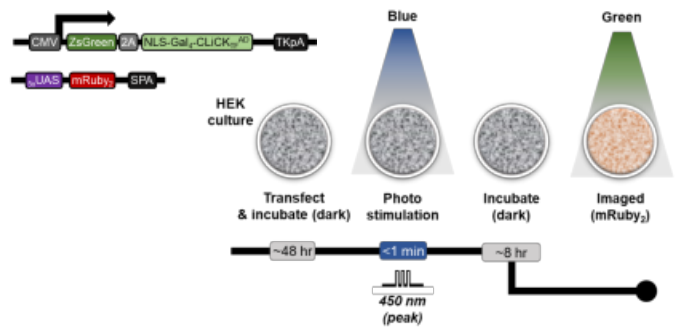

f
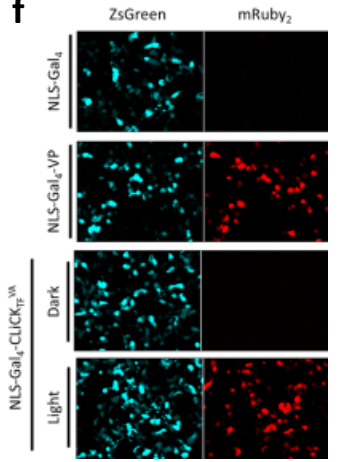

g

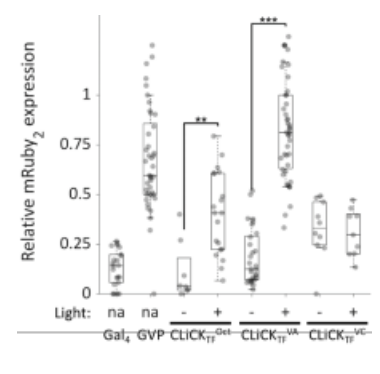

Figure 1. Engineering a light-responsive transcription factor: CLiCK. (a) Schematic of light-gated transcription factor, CLiCK In dark conditions, $\mathrm{CLiCK}_{\mathrm{tf}}$ acts to gate gene expression through sterically blocking key catalytic residues along its transcriptional activation domain (Ja-AD). Exposure to blue light induces core conformational changes within Ja-AD which lead to the unfolding and exposure of its transcriptional activation domain, enabling interactions with transcriptional co-factors, as indicated by the arrow on lower right. NLS, nuclear localization sequence; AD, activation domain. (b) Example ribbon model of CLiCK $\mathrm{ttfivP}_{16 \mathrm{E}}$ in low-energy dark state as determined by iterative template fragment assembly simulations. An NLS-Gal 4 - domain (cyan-purple) is linked by a flexible GS linker to the N-terminus of the phototropin AsLOV 2 (green) from Avena sativa. At its C-terminus, a chimeric Ja-transactivation domain is contained (yellow). Photo-sensitive chimers were evaluated in silico from their amino acid sequences. Predicted characteristics of depict favorable dark-state packing (solvent accessibility $=2$ ) and stability (normalized B-Factor $=-0.15$ ) of presumptive critical residue F261. Normalized $\beta$-Factor values below 0 indicate stable residuals; predicted solvent accessibility range from 0 (highly (b)uried, shown by letter "b" in figure) to 9 (highly (e)xposed, shown by letter "e" in figure). (d) The Ja-domain amino acid sequence of wild-type AsLOV 2 (236-260) and the minimal activation motifs of VP16 (435-447) and Oct (143-160) showing the four Ja-AD permutations originally selected from in silico models for testing in vitro. Color of residue letters: Ja, blue; transactivators VP16 or Oct, purple; chimeric, cyan. Small-case depicts linker. Background coloring indicates Ja region and putative transactivation domain. (e) Schematic representation of the fluorescence reporter system for testing $\mathrm{CLiCK}_{\mathrm{tf}}$ light-gating in vitro. (top) The diagram illustrates the constitutively expressed fluorescence transfection marker (ZsGreen) expression cassette that contains the transgene for a CLiCK $\mathrm{K}_{\mathrm{tf}}$ $\mathrm{NLS}_{-} \mathrm{Gal}_{4}$ (negative control) or NLS-Gal 4 -VP16 (positive control) and its corresponding ${ }_{5 \times}$ UAS target in the fluorescence functional reporter (mRuby2) vector. (bottom). 2A; self-cleavage peptide. Dissociated HEK293 cells were co-transfected with a CLiCK

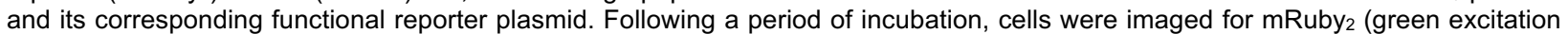
light) then either briefly exposed to blue light or returned to light-tight containers without exposure to blue light. After 6 hours cells were imaged for mRuby2. When not being transfected, imaged, or photo-activated, cells were kept in light-tight containers. (f) Example images of $\mathrm{CLiCK}_{\mathrm{tf}}{ }^{\mathrm{VA}}$ light-responsive expression of mRuby2. Top row shows negative control of mRuby $\mathrm{m}_{2}$ expression under transcription factor with activation domain removed (NLS-Gal 4$)$. Top middle row shows positive control of mRuby2 expression under a lightindependent transcription factor (NLS-Gal 4 -VP). Bottom middle row shows of mRuby2 expression under photo-sensitive transcription factor (NLS-Gal $4-\mathrm{CLiCK}_{\mathrm{ff}}^{\mathrm{VA}}$ ) in absence of light. Bottom row shows of mRuby 2 expression under photo-sensitive transcription factor $\left(\mathrm{NLS}_{-} \mathrm{Gal}_{4}-\mathrm{CLiCK}_{\mathrm{tf}}^{\mathrm{VA}}\right.$ ) following brief photo-stimulation. (g) Relative mRuby2 expression from imaging data plotted with boxplot superimposed. The three different $\mathrm{CLiCK}_{\mathrm{tf}}$ chimeras showed differential light-responsive expression of mRuby 2 where $\mathrm{CLiCK}_{\mathrm{tf}}^{\mathrm{VA}}$ had the greatest dynamic range. $C_{\text {LiCK }}$ Oct: $0.11 \pm 0.15, n=861$ (-Light), $0.40 \pm 0.21, n=2184$ (+Light), $P=0.001-0.01 ; C L_{i C K}{ }_{t f}{ }^{A}: 0.19$ $\pm 0.14, \mathrm{n}=1811$ (-Light), $0.83 \pm 0.25, \mathrm{n}=2397$ (+Light), $\mathrm{P}<0.001$. Boxes show median line, $25^{\text {th }}$ and $75^{\text {th }}$ percentiles edges and $\mathrm{min} / \mathrm{max}$ outlier whiskers. Two sample T-tests were performed. ${ }^{* *} p<0.001,{ }^{* *} p=0.001-0.01,{ }^{*} p=0.01-0.05$. Reported values are the means, standard deviations, and cell counts for each condition. CMV: cytomegalovirus, 2A: 2A self-cleaving peptide, NLS: nuclear localization sequence, $\mathrm{Gal}_{4}$ : $\mathrm{Gal}_{4}$ DNA binding domain, TKpA: tymidine kinase polyadenylation, UAS: upstream activation sequence, SPA: synthetic polyadenylation. 
To identify ADs suitable for caging within $\mathrm{AsLOV}_{2}$, we searched for candidates that were biochemically similar to the J $\alpha$-helix and two transactivator peptides were chosen: the virion protein 16 of herpes simplex virus type 1 (VP16) and the lymphocyte-derived octamer transcription factor 2A (Oct). The amphipathic $\alpha$-helix of VP16 contains a minimal activation motif (VP16437-447) DALDDFDLDML capable of inducing expression in either proximal or remote locations ${ }^{32}$. VP16437-447 negative residues D443 and D445 are critical for initial docking interactions while hydrophobic residues L439, F442, and L444 are critical for stable transcriptional activity with residue F442 particularly critical ${ }^{33}$. The Oct minimal activation motif (Oct $143-160)$ NLFQLPQQTQGALLTSQP induces proximal transcriptional activation ${ }^{32,34}$. As mutations deep inside the $\mathrm{J} \alpha$-helix are more likely to disrupt adduction into the $\beta$-sheets of $\mathrm{AsLOV}_{2}$, we designed preliminary $\mathrm{J} \alpha-\mathrm{AD}$ permutations which focused towards the outer segment of the J $\alpha$-helix. Those permutations conserved hydrophobic residues I539, A542, and A543 known to make critical contacts with $\mathrm{AsLOV}_{2}$ domain $\beta$-sheets ${ }^{35,36}$.

The I-TASSER protein modeling suite ${ }^{37}$ was used to construct high quality models to identify favorable J $\alpha$-AD chimeric sequences (Fig. 1b). For each chimeric sequence an average of 9,869 simulations was performed, generating a large ensemble of structural conformations from which five full length atomic models were constructed. Structural and functional analyses were performed using the models with the greatest confidence score. Impacts of AsLOV $\mathrm{V}_{2} \mathrm{~J} \alpha$ alterations on stability of J $\alpha$-AD segments, particularly along key hydrophobic residues, were evaluated for impact on gating integrity (Fig. 1c). General stability of J $\alpha$-ADs was determined by averaging predicted inherent thermal mobility (B-factor) of its residues. Additionally, solvent accessibility of individual residues along $\mathrm{J} \alpha$-ADs was examined to determine if particular residues packed favorably against the protein core. Finally, to assess for any fundamental 
disruption of $\mathrm{AsLOV}_{2}$ photo-transduction capability, the ability of chimeric sequences to bind FMN was examined using protein-protein interaction methods COFACTOR ${ }^{38}$ and COACH. Chimeric models were benchmarked against a model of wildtype $\mathrm{AsLOV}_{2}{ }^{404-546}$ ( ${ }^{\mathrm{wt}} \mathrm{AsLOV}_{2}$ ).

Robust confidence scores of chimera models ranged from 0.83 to $0.97(\mu=0.88)$.

Estimated root-mean-square deviation (RMSD) ranged from $2.9 \AA$ to $3.1 \AA(\mu=3.0 \AA)$, falling within previously established resolutions for functionally predictive models. All models were found to maintain high confidence $(\mu=0.97)$ of FMN binding at their corresponding C450 binding pocket of ${ }^{\mathrm{wt}} \mathrm{AsLOV}$, suggesting compatibility of J $\alpha$-AD sequences to dock with core $\beta$ sheets. Predicted $\beta$-factors (BFP) for J $\alpha$-ADs ranged from -0.3 to 0.1 , where BFP values higher than 0 are less stable, and were found comparable to ${ }^{\mathrm{wt}} \mathrm{AsLOV}_{2}\left(\mathrm{BFP}_{\mathrm{J} \alpha}=0.14\right)$. Chimeric sequences showing favorable dark-state packing and stability of critical residues were genetically engineered for in vitro assays (Fig. 1d).

To evaluate the gating properties of each chimera, a photo-activation assay was performed in human embryonic kidney (HEK293) cells (Fig. 1e). Cells were co-transfected with two plasmids: 1) an NLS-Gal 4 - $\mathrm{CLiCK}_{\mathrm{tf}}$ chimera placed under a constitutive promoter, and 2) a ${ }_{5 \mathrm{x}} \mathrm{UAS}-\mathrm{mRuby}{ }_{2}$ target reporter with a transfection marker (ZsGreen). For positive controls, an NLS-Gal $4-\mathrm{VP} 16_{\mathrm{tf}}$ replaced NLS-Gal $4-\mathrm{CLiCK}_{\mathrm{tf}}$. For negative controls, VP16 $6_{\mathrm{tf}}$ was removed from the positive construct. Following transfection, cells were kept in light-tight containers. To induce light-dependent gene expression, cells were briefly exposed to 1 second pulses of blue light (450 $\mathrm{nm}$ peak, $12 \mathrm{~mW}$ ). Following photo-stimulation, cells were immediately returned to light-tight containers where they remained until imaging. All experiments were carried out in lightcontrolled environments. 
With the exception of $\mathrm{CLiCK}_{\mathrm{tf}} \mathrm{VB}$ (data not shown), all $\mathrm{CLiCK}_{\mathrm{tf}}$ chimeras were capable of driving mRuby2 expression. Only $\mathrm{CLiCK}_{\mathrm{tf}}{ }^{\mathrm{Oct}}$ and $\mathrm{CLiCK}_{\mathrm{tf}}{ }^{\mathrm{VA}}$ showed light-dependent dynamic expression (Fig. 1g). $\mathrm{CLiCK}_{\mathrm{tf}}{ }^{\mathrm{VA}}$ produced a particularly strong response to light, a 6-fold increase in expression compared to $\mathrm{NLS}-\mathrm{Gal}_{4}-\mathrm{J}_{\alpha} \mathrm{VA}$. Additionally, $\mathrm{CLiCK}_{\mathrm{tf}}{ }^{\mathrm{VA}}$ dark-state expression did not differ from NLS-Gal 4 negative controls, $\sim 12 \%$ to $14 \%$ respectively.

We exploited the endogenous signaling pathway of intranuclear DREAM (downstream responsive element antagonist modulator) ${ }^{39,40}$ as a sensor for ${ }_{i n} \mathrm{Ca}^{2+}$ transients that are associated with activity-dependent gene expression (Fig. 2a). In neurons, DREAM functions as a principal transcriptional switch regulating the on/off status of specific activity-dependent gene expression

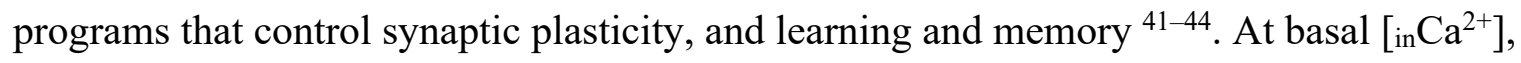
DREAM binds to a downstream regulator element (DRE) within promoter regions of the genome. Upon rising $\left[\mathrm{inCa}^{2+}\right], \mathrm{Ca}^{+}$binds directly to DREAM inducing its dissociation from the DRE ${ }^{39,45-48}$. The conserved, orientation-independent ${ }^{41}$, sequence "GTCA" forms the core of DRE motifs while flanking nucleotides determine DREAM binding affinity ${ }^{49,50}$.

TATTTTGGACTGG GTA (iDRE), from the inducible cAMP early repressor gene (ICER), has previously been shown to bind tightly to DREAM ${ }^{49}$. To minimize $\mathrm{Ca}^{2+}$-independent expression of the reporter, iDRE was incorporated into the DNA vector between the UAS and mRuby2 so that expression could be gated by both light and nuclear $\mathrm{Ca}^{2+}$ (Fig. 2b). In addition to iDRE, we tested GGAGTCAGC (cDRE) from the presumptively high-affinity cross-species prodynorphin consensus DREs, PuNGTCAPuPuG ${ }^{50}$. 
bioRxiv preprint doi: https://doi.org/10.1101/2021.12.05.471336; this version posted December 7, 2021. The copyright holder for this preprint (which was not certified by peer review) is the author/funder, who has granted bioRxiv a license to display the preprint in perpetuity. It is made available under aCC-BY-ND 4.0 International license.

a

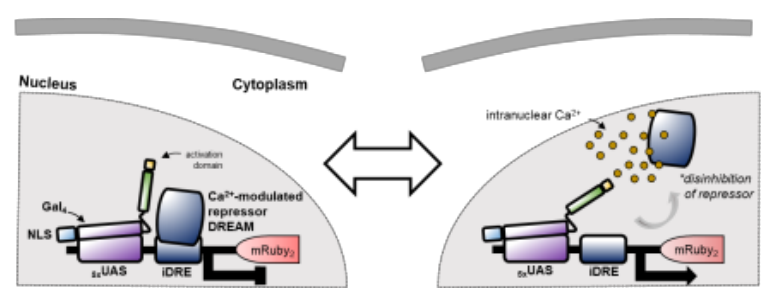

b

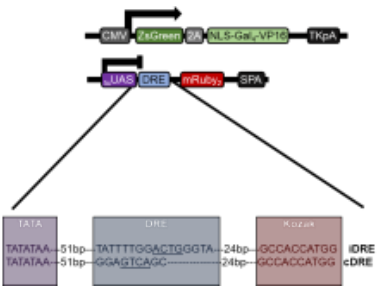

C

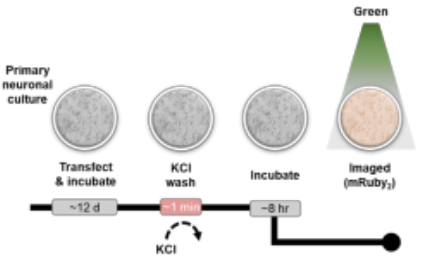

d

ZsGreen mRuby $_{2}$
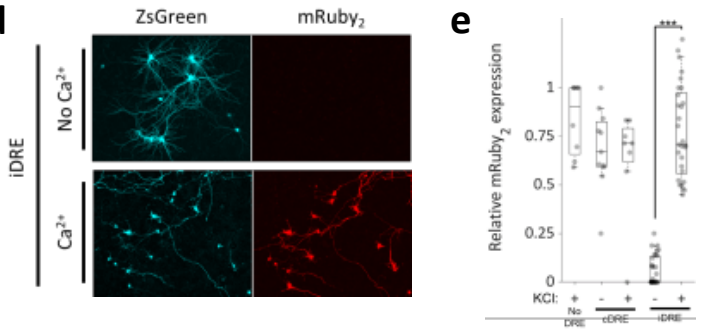

Figure 2. Engineering of CLiCK's intranuclear $\mathrm{Ca}^{2+}$-gate. (a) Schematic overview of intranuclear $\mathrm{Ca}^{2+}$-gated expression system. At basal intranuclear $\mathrm{Ca}^{2+}\left(\right.$ in $\left.\mathrm{Ca}^{2+}\right)$, DREAM represses downstream gene expression. Ion fluxes of inCa ${ }^{2+}$ cause dissociation of DREAM from its binding sequence through direct $\mathrm{Ca}^{2+}$ interactions, relieving transcriptional repression. (b) Schematic representation of constitutively expressed transactivator (top) and its downstream in $\mathrm{Ca}^{2+}$-dependent fluorescence reporter (middle) containing either an iDRE or cDRE motif (bottom). (c) In vitro neuronal assay design for activity-induced in $\mathrm{Ca}^{2+}$-dependent expression of mRuby2. Dissociated E15 rat primary cortical neurons in culture were co-transfected with a vector set depicted in and incubated for $\sim 12$ days. To induced activity driven intranuclear $\mathrm{Ca}^{2+}$ transients, $20 \mathrm{mM}$ of $\mathrm{KCl}$ was applied to the culture media and rapidly washed out with preconditioned media (see Methods). Immediately following a $\mathrm{KCl}$ wash, cells were returned to the incubator for 6-8 hours before imaging for expression of mRuby2. (d) Example images of $\mathrm{CLiCK}_{\text {act }}{ }^{\text {iDRE }}$ showing ${ }_{\text {in }} \mathrm{Ca}^{2+}$-gated expression of $\mathrm{mRuby}{ }_{2}$ for $\mathrm{KCl}$ induce neural activity (bottom) and TTX treat control (top). (e) Relative mRuby 2 expression from imaging data plotted with boxplot superimposed. No DRE: (+) $0.84 \pm 0.18, \mathrm{n}=137$; cDRE: (-) $0.69 \pm 0.2, \mathrm{n}=236$ and $(+) 0.64 \pm 0.27, \mathrm{n}=43$; iDRE: (-) $0.06 \pm 0.08, \mathrm{n}=$ 654 and $(+) 0.78 \pm 0.23, \mathrm{n}=1818$. Boxes show median line, $25^{\text {th }}$ and $75^{\text {th }}$ percentiles edges and $\mathrm{min} / \mathrm{max}$ outlier whiskers. Two sample T-tests were performed. ${ }^{* *} p<0.001,{ }^{* *} p=0.001-0.01,{ }^{*} p=0.01-0.05$. Reported values are the means, standard deviations, and cell counts for each condition. 
All vector sets containing the dual DNA sensors express mRuby2 in the absence of DREAM, as assessed by transfection assays in HEK cells which do not express endogenous DREAM protein. To evaluate $\mathrm{Ca}^{2+}$-dependent gating capacities of $\mathrm{iDRE}$ and cDRE within the new mRuby 2 vector, we used a conditional activity-induced in vitro neural assay (Fig. 2c). Primary neuronal cultures were co-transfected with CMV-NLS-Gal4-VP16-2A-ZsGreen (where $2 \mathrm{~A}$ is a self cleaving peptide sequence) and a vector containing a ${ }_{\mathrm{x}} \mathrm{UAS}-\mathrm{DRE}-\mathrm{mRuby} 2$ reporter with either the iDRE or cDRE sequence positioned between the UAS and mRuby2. For a positive control, neurons were transfected with the $\mathrm{Ca}^{2+}$-independent ${ }_{5 \mathrm{x}} \mathrm{UAS}-\mathrm{mRuby} 2$ reporter. While cDRE was ineffective at repressing $\mathrm{mRuby}_{2}$ expression in absence of ${ }_{\text {in }} \mathrm{Ca}^{2+}$, iDRE tightly regulated expression with basal levels of $6 \%$ compared to $78 \%$ in the absence of DREAM, a 13 fold dynamic range (Fig. 2e). Moving forward, the iDRE cassette was engineered into the dual $\mathrm{Ca}^{2+}$-light gated expression system called CLiCK.

CLiCK contains a photo-sensitive transactivator $\left(\mathrm{CLiCK}_{\mathrm{tf}}\right)$ and a direct ${ }_{\text {in }} \mathrm{Ca}^{2+}$-regulated expression cassette $\left(\mathrm{CLiCK}_{\mathrm{act}}\right)$. These two gates operate in tandem, simultaneously gating gene expression (Fig. 3a). $\mathrm{KCl}$ induced-activity and light exposure was combined to determine whether coincidence gating of the fluorescent $\mathrm{mRuby}_{2}$ reporter could be detected in primary neuronal cultures under the following four conditions: inactive-dark, inactive-light, active-dark, and active-light (Fig. 3b). Briefly, to evaluate baseline expression levels of $\mathrm{mRuby}_{2}$ in the coabsence of both light and activity (inactive-dark), cells were kept in light-tight containers and treated with $1 \mu \mathrm{M}$ of TTX to suppress spontaneous neural activity. Baseline leak of expression through each gate was examined by individually applying either the $\mathrm{KCl}$ or light assay as described in Figures 1e and 2c with the supplemental treatment of TTX to block spontaneous neural activity in the light assay (see Methods). Reporter expression (mRuby 2 ) under the co- 
occurrence of activity and light (active-light) was examined by the simultaneous application of $\mathrm{KCl}$ and light protocols. To temporally define the window of activity upon exposure to light, culture media was immediately exchanged with $\operatorname{TTX}(1 \mu \mathrm{M})$ conditioned media following all $\mathrm{KCl}$ washes. Immediately following all conditions, cells were returned to light-tight containers and incubated for 6 hrs before imaging. With relief of both $\mathrm{Ca}^{2+}$ and light gates, mRuby2 expression increased by 19-fold compared to expression in the absence of activity and light (Fig. 3d). When both gates are engaged, we observed minimal expression (transcriptional leakage) of mRuby $_{2}$ (mean of $3.9 \%$ ). With the release of either gate, leak increased slightly where $5.8 \%$ is observed through the $\mathrm{Ca}^{2+}$ gate and $12.9 \%$ through the light gate. Though transcriptional leakage is more prominent in active cells under dark conditions, it is comparable to baseline observed in HEK cells (Fig. 1g). 
bioRxiv preprint doi: https://doi.org/10.1101/2021.12.05.471336; this version posted December 7, 2021. The copyright holder for this preprint (which was not certified by peer review) is the author/funder, who has granted bioRxiv a license to display the preprint in perpetuity. It is made available under aCC-BY-ND 4.0 International license.

a

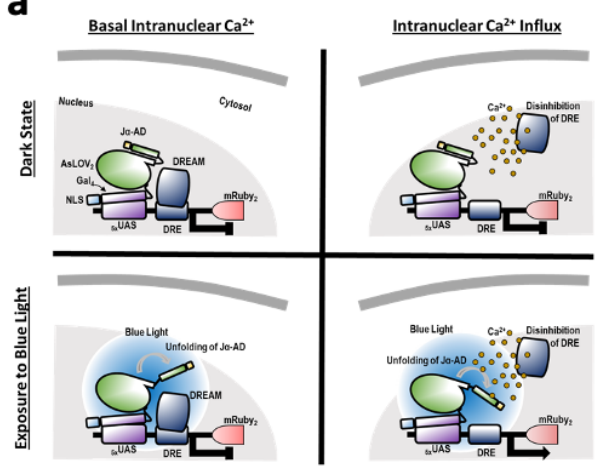

b
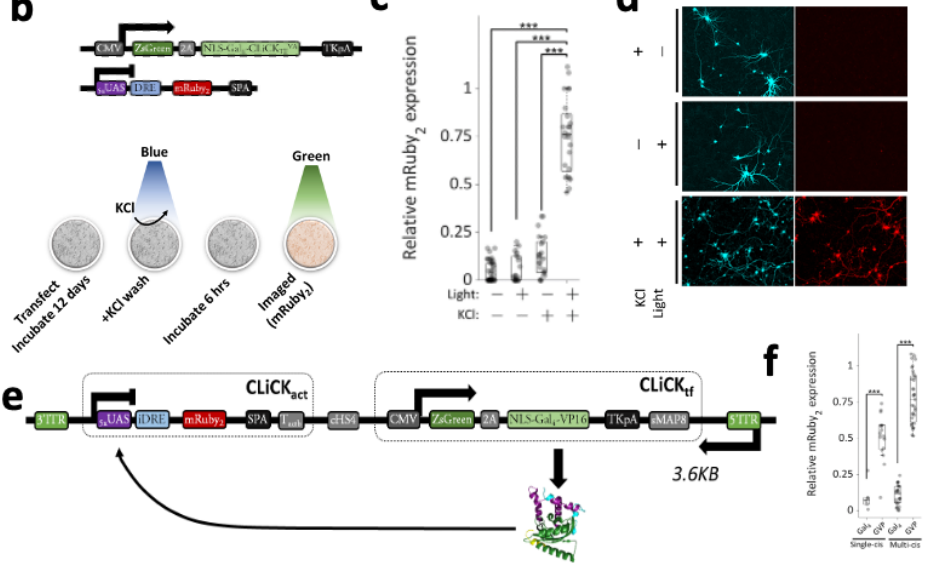

g
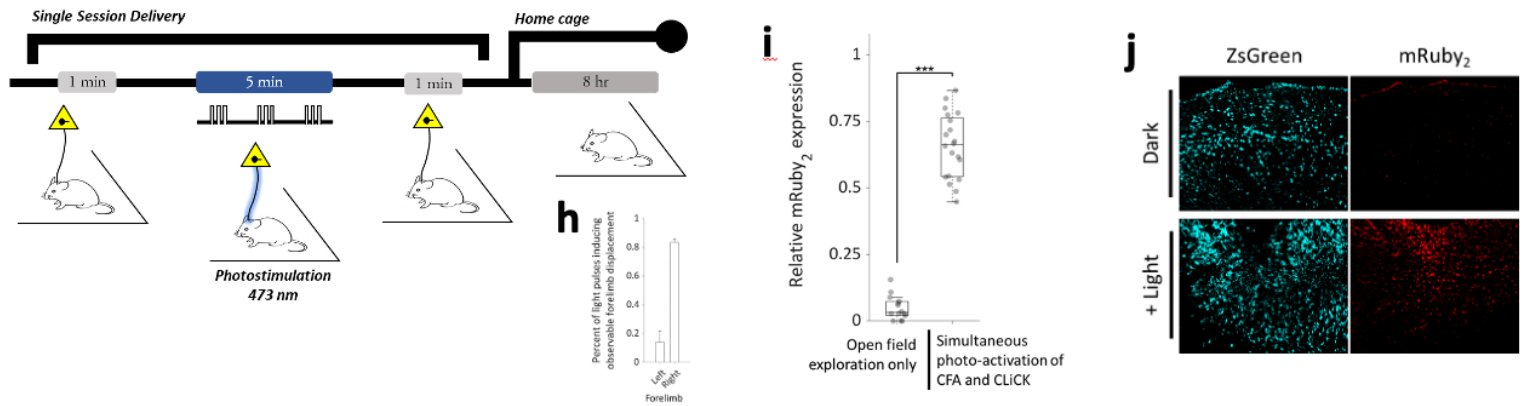

Figure 3. Evidence for ${ }_{\text {in }} \mathrm{Ca}^{2+}$-light coincident expression and a platform for in vivo optimization and future use. (a) Schematic of CLiCK. Combining gates depicted in Figures $1 a$ and $2 a$, CLiCK gates gene expression through two independent gatingmechanisms: (1) an intranuclear $\mathrm{Ca}^{2+}$-gated repressor and (2) a light-gated transcription factor. In the absence of either blue light or activity-induced ${ }_{i n} \mathrm{Ca}^{2+}$, transcription of the mRuby, transgene is blocked. The mRuby 2 reporter is only detected upon the co-occurrence of activity-induced increases in in $\mathrm{Ca}^{2+}$ and the presence of blue light. Neither alone is enough to induce its gene expression. (b) Schematic representation of the (top) CLiCK fluorescence reporter system and (bottom) in vitro neuronal assay design used for light and activity coincidence expression of mRuby2. (c) Relative mRuby 2 expression from imaging data plotted with boxplot superimposed. $(-/-)$ no stimuli: $0.04 \pm 0.05, \mathrm{n}=1221, \mathrm{P}<0.001 ;(+/-)$ induced-activity only: $0.13 \pm 0.10, \mathrm{n}=990, \mathrm{P}<0.001 ;(-/+)$ blue light only: 0.06 $\pm 0.07, n=591, P<0.001 ;(+/+)$ induced-activity and blue light: $0.75 \pm 0.19, n=838, P<0.001$. (d) Example images of CLiCK coincidence gating of mRuby2. (e) Schematic circuit design for single vector CLiCK. Consists of two expression cassettes, CLiCK act $_{2}$ and $\mathrm{CLiCK}_{\mathrm{tf} .}$ A gene-of-interest can be easily inserted in-frame via Agel and Notl restriction sites within CLiCK is inserted between expression cassettes, and a transcriptional pause sequence ( $T_{\text {act }}$ and sMAP8) was inserted near the end of each expression cassette. Length of entire vector is $3626 \mathrm{bp}$ (without reporter) and $4340 \mathrm{bp}$ with reporter mRuby ${ }_{2}$ as conditional reporter transgene. (f) Relative mRuby2 expression differences between multi-plasmid and single-plasmid vector designs of CLiCK. To characterize the dynamic ranges of mRuby ${ }_{2}$ expression between single-vector and multi-vector designs, a NLS-Gal $4_{4}-\mathrm{VP}$ (labelled as GVP in the figure) transcription factor was used to evaluate peak expression. To characterize minimal expression the activation domain $\mathrm{VP}_{16}$ was removed from the transcription factor (labelled as $\mathrm{Gal}_{4}$ in the figure). Relative expression was as follows: Single-cis: $0.09 \pm$ $0.09, \mathrm{n}=442\left(\mathrm{Gal}_{4}\right), 0.51 \pm 0.16, \mathrm{n}=1335$ (GVP), $\mathrm{P}<0.001$; multi-cis: $0.11 \pm 0.06, \mathrm{n}=2218\left(\mathrm{Gal}_{4}\right), 0.78 \pm 0.17, \mathrm{n}=3915$ (GVP), $\mathrm{P}$ $<0.001$. (g) Schematic for testing CLiCK in vivo. An AAV $2 / 9$ virus encoding the entirety of CLiCK (including the transduction marker ZsGreen and conditional reporter mRuby ${ }_{2}$ ) was injected bilaterally into the caudal forelimb area (CFA) of the motor cortex of Thy1ChR2 transgenic mice. To induce activity in only the right forelimb, a single optical fiber was implanted in the left hemisphere targeting the CFA. For photo-induction, a $473 \mathrm{~nm}$ light was delivered to the left CFA at $9.6 \mathrm{~mW}$ (measured at pre-implanted fiber tip). Light pulses of $10 \mathrm{~Hz}$ ( $100 \mathrm{~ms}$ period) were delivered at $50 \%$ duty cycle ( $50 \mathrm{~ms}$ ON, $50 \mathrm{~ms}$ OFF) for one second. In total, 50 light pulses (5 sec interpulse intervals) were delivered per session. Sessions lasted a total of 5 mins. Following stimulation, mice were returned to their home cage for $8 \mathrm{hrs}$ then perfused for imaging analysis. (h) Summary of behavioral data. Average number of light-induced forelimb displacements observed per session (left 5 mice; right 4 mice). (i) Summary of cell count results in postmortem tissue after behavioral experiment. In absence of light (right hemisphere), exploration of an open field did not induce expression of $\mathrm{mRuby}_{2}$ in the CFA. Delivering light pulses (left hemisphere) during exploration of an open field induced behavioral activation of the contralateral forelimb and expression of mRuby2. Open field only: $0.03 \pm 0.04(n=1120$ cells $/ 5$ mice $)$; co-activation: $0.66 \pm 0.12(n=1479$ cells $/ 4$ mice), $P<0.001$. (j) Representative brain sections from experiment in (g) for non-light activated (top) and light co-activated ChR and CLiCK (bottom). Left hemisphere received photostimulation protocol, whereas right hemisphere was kept in the dark. Simultaneous light induced CFA activity and CLiCK drives expression of mRuby2 in the light condition (bottom) but not in the dark condition (top). Boxes show median line, 25th and 75th percentiles edges and $\mathrm{min} / \mathrm{max}$ outlier whiskers. Two sample T-tests were performed. ${ }^{* * *} p<0.001,{ }^{* *} p=0.001-0.01,{ }^{*} p=0.01-0.05$. Reported values are the means, standard deviations, and cell counts for each condition. 
To prepare CLiCK for practical use in experimental settings, the entirety of CLiCK $(<2.5$ KB ) was engineered into a single multicistronic AAV vector (Fig. 3e) leaving, minimally, 2.3 KB for insertion of a conditional transgene. In its concise form, CLiCK contains two expression cassettes: (1) $\mathrm{CLiCK}_{\mathrm{act}}$ and (2) $\mathrm{CLiCK}_{\mathrm{tf}}$. The promoter region of $\mathrm{CLiCK}_{\mathrm{act}}$ contains an iDRE binding sequence $51 \mathrm{bp}$ downstream of a ${ }_{5 \mathrm{x}} \mathrm{UAS}$ sequence and $24 \mathrm{bp}$ upstream from the Kozak sequence recognized by the ribosome. Conditional transgenes can be easily inserted in-frame via AgeI and NotI restriction sites. $\mathrm{CLiCK}_{\mathrm{tf}}$ contains genes that encode a transduction marker (ZsGreen) and the photo-switchable transcription factor $\mathrm{CLiCK}_{\mathrm{tf}}$, separated by a P2A self cleaving peptide sequence. The $\mathrm{CLiCK}_{\mathrm{tf}}$ gene was placed downstream of the P2A to avoid addition of undesired residues left behind by cleavage. To enhance stable transcription termination and avoid conditional expression leaks arising from runoff transcription, $\mathrm{CLiCK}_{\mathrm{act}}$ was placed upstream of $\mathrm{CLiCK}_{\mathrm{tf}}$ and a pause sequence (Tact and sMAP8, respectively) was inserted near the end of each expression cassette ${ }^{51}$. Expression variability through unintended enhancer activity or position effects of transgenes, was minimized using an insulator sequence (cHS4) inserted between expression cassettes. Changes in $\mathrm{mRuby}_{2}$ expression under positive conditions were evaluated in HEK cells using a Gal4-VP16 transcription factor (Fig. 1g). For negative controls, the VP16 activation domain was removed such that only the $\mathrm{Gal}_{4}$ DNA binding domain remained (see Methods for details). Compared to delivery of CLiCK via multiple vectors, we found positive expression of mRuby2 under a single multicistronic vector increased by $28 \%$, indicating improved delivery of the complete package of transgenes (Fig. 3f).

Most importantly, the potential in vivo application of CLiCK was tested using ThylChR2-YFP mice $(\mathrm{n}=5)$ (Jackson Labs; B6.Cg-Tg(Thy1-ChR2/EYFP)18Gfng/J), a mouse line that has been engineered to express channel rhodopsin 2 under control of the thymus antigen 1 
(Thy1) promoter. The caudal forelimb area (CFA) of the mouse motor cortex was bilaterally injected with a recombinant AAV containing CLiCK (Fig. 3g). A fiber optic targeting the CFA was unilaterally implanted in the left hemisphere of each mouse such that photo-activation of the left CFA would produce displacement of the right forelimb. The right hemisphere was treated as a dark control. Following 3 weeks post-surgery, mice were placed in an open field $(91 \mathrm{x} 91 \mathrm{~cm})$ and a brief photo-stimulation protocol was implemented (for details see Methods). For photoinduction, a $473 \mathrm{~nm}$ light was used which activates both ChR2 and CLiCK's photo-switchable transcription factor. A light pulse of $10 \mathrm{~Hz}(100 \mathrm{~ms}$ period) was delivered at $50 \%$ duty cycle (50 ms ON, $50 \mathrm{~ms}$ OFF) for one second. In total, 50 light pulses ( $5 \mathrm{sec}$ interpulse interval) were delivered per mouse. Sessions lasted a total of 5 mins. Following photo-stimulation, mice were returned to their home cage for $8 \mathrm{hrs}$ then perfused for imaging analysis. On average, photostimulation of the left CFA induced an observable right forelimb displacement for $83 \%$ of the light pulses delivered in a session (Fig. 3h). Without photo-stimulation, free mobility of the forelimbs in open field exploration produced $<5 \%$ expression leak of mRuby ${ }_{2}$ in CFA cells $(n=$ 1120 cells/5 mice) (Fig. 3i). With the co-occurrence of light and forelimb activity, there was a 13-fold increase of mRuby 2 expression in the CFA ( $n=1479$ cells $/ 4$ mice).

We have identified and addressed three crucial characteristics currently limiting the potential of current technologies. These include a (i) poor temporal resolution in the temporal windowing of signal (activity) -dependent gene transcription, (ii) signal ambiguity through divergent signal transduction pathways, and (iii) impractically complex packaging of genetic material. Collectively, these limitations present a very real barrier between the application and potential of optogenetic tools. 
To address limitations in the temporal resolution of physiologically conditioned (activitydependent) gene transcription we engineered a light-sensitive transcription factor which minimizes both the number of molecular events and physical distance between the site of light transduction and the site of gene transcription to within the nucleus of the cell. To dispel ambiguity in the signal transduction of neural activity we incorporated a direct nuclear $\mathrm{Ca}^{2+}$ modulated repressor upstream of our reporter gene. Finally, through concise genetic design and encoding we are able to package and deliver the entirety of our system within a single AAV vector, thus overcoming practical barriers in its application in vivo. Together, these features offer a potential platform technology for the practical application in studies of neural activity patterns.

In our in vivo proof of concept study, we used light to drive both neural activity (via channelrhodopsin) and the unfolding of CLiCK's light-sensitive transcription factor. This allowed us to link a behavioral readout (displaced limb movements) to anatomically specific expression of mRuby 2 in the CFA of M1. With the combined vector, we observed that transcription of the reporter mRuby2 corresponded with a decreased expression of the transduction marker, ZsGreen (Fig. 3j). This may be due to a competition in the molecular cofactors required for transcription of nearby genes, especially with increased activation of one promoter, or epigenetic modification of the CMV promoter driving the transduction marker. When we delivered CLiCK via two vectors ( $3 \mathrm{~b}$ top) we observed continuous expression of both the ZsGreen and mRuby2 with the co-occurrence of light and $\mathrm{KCl}$ induced $\mathrm{Ca}^{2+}(3 \mathrm{~d})$.

As this technology continues to be develop, I am particularly interested in exploring its applications in translational and clinical neuroscience to address unmet medical needs in mental health conditions. I believe there are several points along the development of a therapeutic candidate which precise experimental control of activity-dependent gene transcription would be 
bioRxiv preprint doi: https://doi.org/10.1101/2021.12.05.471336; this version posted December 7, 2021. The copyright holder for this preprint

(which was not certified by peer review) is the author/funder, who has granted bioRxiv a license to display the preprint in perpetuity. It is made available under aCC-BY-ND 4.0 International license.

useful, if not groundbreaking. These include, but not limited to, the development of new

neurocircuit-based animal disease models, behaviorally relevant (functional) transcriptomics, and behaviorally-targeted delivery of new gene therapy candidates. 


\section{Methods}

\section{In Silico Modeling}

To construct high-quality predictions of 3D protein structure and function from amino acid sequences an Iterative Threading ASSEmbly Refinement (I-TASSER) algorithm was adopted. The I-TASSER algorithm consists of 3 consecutive steps of threading, fragment assembly, and iteration ${ }^{52-54}$. 3D models were visualized and plotted using the Python package for molecular visualization, PyMOL.

\section{Molecular Cloning}

Photo-switchable chimerics: To create the functional domains (DNA binding domain ( $\left.\mathrm{Gal}_{4}\right)$, photo-sensitive core $\left(\mathrm{AsLOV}_{2}\right)$, and transcription activation domain (AD) of $\mathrm{CLiCK}_{\mathrm{tf}}$, we incorporated and synthesized DNA fragments from multiple sources. For the light sensitive core of the $\mathrm{CLiCK}_{\mathrm{tf}}$, the LOV protein was used in combination with other elements. The expression construct for Avena sativa phot1 LOV2 (Uniport O49003_AVESA) was generously provided by Dr. Andreas Möglich (Humboldt University of Berlin) in a ET-28c plasmid. The Gal ${ }_{4}$ DNA binding domain and UAS promoter sequence was generously provided by Dr. Ben Wolozin (Boston University) in a pCI-neo plasmid. Single-stranded NLS and Ja-activation domain oligonucleotides were synthesized using Integrated DNA Technologies custom DNA service. Oligos $\leq 60$ nucleotides were purified using standard desalting purification while oligos $>60$ nucleotides were purified using PAGE. Oligos were resuspended in nucleus-free buffer and annealed at equal molar concentrations. For in-frame cloning of $J \alpha$-activation domains into the N-terminus of AsLOV 2 , overlap extension PCR ${ }^{55}$ was used. AsLOV-Ja-AD PCR products were then cloned in-frame into $\mathrm{pGal}_{4}-\mathrm{Cl}$ backbones using standard digest and ligation protocols. For $\mathrm{Gal}_{4}-\mathrm{J} \alpha-\mathrm{AD}$ constructs, double stranded J $\alpha$-AD oligos were used to clone into the pGal 4 -CI. 
Direct intranuclear $\mathrm{Ca}^{2+}$-dependent repressor of expression. Another component of the system, $\mathrm{CLiCK}_{\mathrm{act}}$, was engineered to repress gene transcription in a intranuclear $\mathrm{Ca}^{2+}$-dependent manner. To engineer the functional domains of $\mathrm{CLiCK}_{\mathrm{act}}$ (UAS promoter region, DNA downstream regulatory element (DRE), reporter gene (mRuby2)) we incorporated and synthesized DNA fragments from multiple sources. pmRuby2-N1 plasmid was obtained from Addgene (accession \# U55762). Single-stranded TATA box and DRE oligonucleotides were synthesized using Integrated DNA Technologies custom DNA service. Oligos were resuspended in nucleus-free buffer and annealed at equal molar concentrations. Standard PCR, digest and ligation protocols were used for subcloning double-stranded TATA, UAS and DRE fragments into pmRuby $2-\mathrm{N} 1$.

Rational optimization for in vivo applications. The expression construct for LVDP ${ }^{51}$ was generously provided by Dr. Stelios T. Andreadis (University at Buffalo, Amherst, NY) in a pCS vector (Addgene plasmid \# 12158).

\section{Cell Cultures}

HEK cultures. To provide an initial in vitro test system, we used cultured HEK cells. HEK cells were plated in $24-w e 11,35 \mathrm{~mm}$ or $100 \mathrm{~mm}$ dishes such that their confluency was approximately $60 \%$ on the day of transfection. Cells were transfected with Lipofectamine 2000 (Thermofisher).

Primary neuronal cultures. To provide an in vitro test system with neurons, we created primary neuronal cultures. Primary hippocampal and neocortical neurons were dissected from embryonic day 18 (E18) Sprague-Dawley rats (Charles River Laboratories). Pregnant dams were euthanized by exposure to $95 \% \mathrm{CO} 2$ and embryos were harvested. Embryonic brains were 
removed and placed in ice-cold $\mathrm{Ca}^{2+} / \mathrm{Mg}^{2+}$ free $(\mathrm{CMF})$ media $\left[\mathrm{Ca}^{2+} / \mathrm{Mg}^{2+}\right.$ free Hank's BSS, 4.2 $\mathrm{mM}$ sodium bicarbonate, $1 \mathrm{mM}$ pyruvate, $20 \mathrm{mM}$ HEPES, $3 \mathrm{mg} / \mathrm{ml} \mathrm{BSA}, \mathrm{pH} 7.25-7.3]$. Relevant brain regions were dissected, homogenized, and centrifuged in plating media [Neurobasal media (Invitrogen), 10\% fetal bovine serum (Gibco), $100 \mathrm{U} / \mathrm{ml}$ penicillin, $100 \mu \mathrm{g} / \mathrm{ml}$ streptomycin, 200 $\mathrm{mM}$ glutamine]. Neurons were plated on poly-L-lysine $(0.1 \mathrm{mg} / \mathrm{mL})$ coated dishes, placed in an incubator $\left(37^{\circ} \mathrm{C} / 5 \% \mathrm{CO} 2\right)$ for one h, after which plating medium was removed and replaced with defined medium [Neurobasal media (Invitrogen), B27 serum-free supplement (Gibco), 100 $\mathrm{U} / \mathrm{ml}$ penicillin, $100 \mu \mathrm{g} / \mathrm{ml}$ streptomycin, $200 \mathrm{mM}$ glutamine]. Cultures were returned to the incubator for approximately 10 days until further use for testing expression and combined activation of reporter by light and calcium activation.

\section{Transfections}

HEK transfections. The following procedures were used in order to transfect the HEK cells with our reporter systems. Plasmid DNA and Lipofectamine (1:3 ratio) were individually diluted in reduced-serum Opti-MEM media, mixed gently and incubated for $5 \mathrm{~min}$ at room temperature. Following incubation, dilutes were combined, mixed gently and incubated for 20 minutes at room temperature. After 20 mins of incubation, DNA-Lipofectamine complexes were added to HEK media in a 1:5 complex-to-media ratio, briefly mixed on a rocker plate and then incubated at $37^{\circ} \mathrm{C}$ in a $5 \% \mathrm{CO} 2$ incubator for $24-48$ hours prior to testing for transgene expression. For light-sensitive experiments, cells were kept in light-tight containers following transfection.

Primary neuronal transfections. The following procedures were used to introduce the genetic components of our systemin cells of neuronal cultures. NeuroMag transfection was 
performed using primary neuronal cultures at 7 DIV, using the NeuroMag Magnetofection ${ }^{\mathrm{TM}}$ kit

(Oz Biosciences \#KC30800). Plasmid DNA was diluted in NBM and added to the NeuroMag

Transfection Reagent. The DNA solution was incubated (20 minutes, room temperature) before

being added to neuronal culture dishes and incubated on a magnetic plate (20 min, room

temperature) provided with the kit. Cells were removed from the plate and incubated $\left(37^{\circ} \mathrm{C}, 5 \%\right.$ CO2) for 10-14 days before assaying.

\section{Cell Assays}

Photo-switchable cell assay. To induce light-dependent transcription, cells were briefly exposed to 1 second pulses of blue light (450 nm peak, $12 \mathrm{~mW}$ ). Following photo-stimulation, cells were immediately returned to light-tight containers and placed into a cell incubator for 6-8 hours prior to imaging. All light sensitive experiments were carried out in a light-controlled environment.

$\mathrm{KCl}$ induced neuronal activity assay. For activity-dependent transcription conditions, intranuclear $\mathrm{Ca}^{2+}$ transients were induced by applying $20 \mathrm{mM}$ of $\mathrm{KCl}$ to neuronal culture media and rapidly washed out using neuronal culture media drawn from the sample 3-7 days prior to assaying. Following $\mathrm{KCl}$ washes, cells were returned to the incubator for 6-8 hours before imaging. To suppress transcription through spontaneous neural activity in negative control conditions, $1 \mu \mathrm{M}$ of TTX was add to the culture media 6-8 hours prior to imaging.

Photo-switchable activity-dependent assay. $\mathrm{KCl}$ induced-activity and light assay designs were combined and coincidence gating of the fluorescent reporter mRuby 2 in primary neuron cultures was examined under four conditions: inactive-dark, inactive-light, active-dark, and active-light. To evaluate leakage of mRuby2 expression in the co-absence of both $\mathrm{iCa}^{2+}$ and light 
(inactive-dark), cells were kept in light-tight containers and treated with $1 \mu \mathrm{M}$ of TTX to suppress spontaneous neural activity. Independent leak of expression through each gate was examined by individually applying either the $\mathrm{iCa}^{2+}$ or light assay (previously described above) with the supplemental treatment of $1 \mu \mathrm{M}$ TTX to culture media to block spontaneous neural activity in the light-alone assay. For co-occurrence of $\mathrm{iCa}^{2+}$ and light (active-light), simultaneous application of $\mathrm{KCl}$ and light protocols was performed. Culture media was immediately exchanged with $1 \mu \mathrm{M}$ TTX preconditioned media following all $\mathrm{KCl}$ washes to create a temporally windowed period of $\mathrm{KCl}$-induced neural activity. Immediately following all lightsensitive conditions, cells were returned to light-tight containers and incubated for 6-8 hrs before imaging.

\section{In Vitro Image Acquisition, Processing, and Analysis}

Image Acquisition. Fluorescent images were collected on an Olympus inverted fluorescence microscope at $10 \mathrm{X}$ and $20 \mathrm{X}$ using a mercury bulb for excitation of fluorophores. ZsGreen was excited at 470/40 nm (center wavelength/bandwidth) and emissions were collected at 525/50 nm, emission (495 $\mathrm{nm}$ dichroic mirror). eYFP was excited at 500/20 nm and emissions were collected at 535/30 nm, emission (515 nm dichroic mirror). mRuby2 was excited at 560/40 $\mathrm{nm}$ and emissions were collected at 630/60 nm, emission (585 $\mathrm{nm}$ dichroic mirror).

Image Processing and Analysis. Automated cell counts were performed in ImageJ using a custom written script. Briefly, images were first convolved with a Gaussian filter with a standard deviation of 2. To avoid erroneous segmentation of non- fluorescent images, background subtractions were performed on images with an intensity distribution kurtosis $>0.4$ using the

Subtract background plugin with a rollsize radius $=0.05 \sqrt{W \times H}$ pixels, where $\mathrm{W}=$ image width 
and $\mathrm{H}=$ image height. Additionally, to automate appropriate thresholding for segmentation, images with an intensity distribution kurtosis $>0.4$ were checked for in mean/median ratio $\geq 1$ and skewness $>0.1$. For images meeting all three criteria, the Triangle ${ }^{56}$ threshold was used, otherwise, the Moments ${ }^{57}$ threshold was used. Next, binary masks were created from thresholds and an erosion and dilation was performed on masks followed by a Watershed segmentation. Particles with an area greater than $4 \sqrt{W \times H}$ pixels squared were the counted using the Analyze Particles plugin.

\section{Mice}

For rapid photo-induced motor behavior, experiments were performed using a transgenic mouse line that expresses the light-activated ion channel, Channelrhodopsin-2, fused to Yellow Fluorescent Protein, in layer 5 cortical neurons under control of the mouse thymus cell antigen 1 (Thy1) promoter (B6.Cg-Tg(Thy1-ChR2/EYFP)18Gfng/J, Jackson Labs). Male and female mice (2-4 months old) were housed by gender in Plexiglas cages together with their siblings before surgery, but separated for individual housing after surgery, and maintained on a $12 \mathrm{~h}$ light/dark cycle. Food and water was provided ad libitum throughout the duration of housing.

\section{Stereotactic Surgeries}

General surgical procedure. All procedures were done in accordance with the Boston University Institutional Animal Care and Use Committee. Surgeries were performed to inject virus containing the CLiCK construct. Viral packaging of CLiCK was performed at Boston Children's Hospital Viral Core. In preparation for surgery, animals were given an injection of atropine (10 mg/kg IP) and buprenorphine (0.1 mg/kg IP) and anesthetized with isoflurane (3\% 
induction, 1-2\% during surgery). Animals were given buprenorphine ( $0.1 \mathrm{mg} / \mathrm{kg} \mathrm{SC})$, ketofen (2$5 \mathrm{mg} / \mathrm{kg} \mathrm{SC})$ and baytril (10 mg/kg SC) during a $5 \mathrm{~d}$ postsurgical care period and given 3 weeks for viral transduction and full recovery before beginning of photo-activation.

Viral transduction. During surgery, the caudal forelimb areas (CFA) (1.0AP, 1.5ML, 0.6DV) of the motor cortex in mice were bilaterally injected with an AAV containing CLiCK. A craniotomy was performed $1 \mathrm{~mm}$ anterior and $1.5 \mathrm{~mm}$ lateral to bregma, and the injection needle (34 g, beveled; WPI) was lowered $0.6 \mathrm{~mm}$ at a $0^{\circ}$ polar angle, following stereotactic coordinates from Paxinos and Franklin (2008). A total of $250 \mathrm{~nL}$ of the pAAV $2 / 9-\mathrm{Gal}_{4}-\mathrm{mRuby}-\mathrm{cHS} 4-\mathrm{CMV}-$ ZsGreen:2A:CLiCK $\mathrm{TF}($ titer $=1.95 \mathrm{E}+13 \mathrm{GC} / \mathrm{mL} ; 0.05 \mathrm{M}$ PBS $)$ was infused at a rate of 100 $\mathrm{nl} / \mathrm{min}$ (UMP3 electrical pump, WPI). Once the full viral injection was delivered the injection needle was left in place for 10 minutes to prevent backflow of the injected virus solution.

Fiber optic implants. Following viral injections, a mono fiber-optic cannula $(200 \mu \mathrm{m}$ core, NA: 0.48; MFC_200/230-0.48_2.5mm_SMR_FLT, Doric Lenses) targeting the CFA (1.0 AP, 1.5 ML, 0.5 DV) was chronically implanted in the left hemisphere such that photo-activation of the left CFA would produce displacement of the right forelimb. The right hemisphere was treated as a dark control. Three anchoring screws were positioned across the skull and, along with the fiber-optic implant, were cemented onto the animal's skull.

\section{In Vivo Experimental Outline}

Open-field environment. Photo-stimulation was carried out as mice explored an openfield environment (1 X $1 \mathrm{~m}$ ) with $60 \mathrm{~cm}$ high black walls. The behavior of the mouse before, during and after laser stimulation of channelrhodopsin was recorded overhead at 30 frames per second (fps) using a 12.2 megapixel CMOS video camera (Sony Exmor IMX363). Photo- 
induced limb displacement during laser stimulation was defined by the co-occurrence of the photo-stimulation and rapid pulsing displacement of the right forelimb due to activation of the left motor cortex.

Photo-stimulation. For simultaneous laser stimulation of ChR2 and CLiCK $\mathrm{tf}_{\mathrm{tf}}$ in mice, a fiber-coupled $473 \mathrm{~nm}$ laser (OBIS FP, Coherent), was digitally modulated via the TTL channel with an Arduino Due microcontroller using a custom built script (see Appendix 2). Laser light was delivered into the brain via a system of fiber patch cords (Thorlabs) and a rotary joint (FRJ_11_FC-FC, Doric Lenses). The last connection was a magnetic connection to the implanted light fiber. The laser light power entering the implanted light fiber was measured before and after every recording session and adjusted before the recording session to yield an estimate of $9.6 \mathrm{~mW}$ laser power delivered into the CFA. Laser stimulation was delivered at $10 \mathrm{~Hz}$ (100 ms period) with a $50 \%$ duty cycle $(50 \mathrm{~ms}$ ON, $50 \mathrm{~ms}$ OFF) for one second with $5 \mathrm{~s}$ interpulse intervals (a typical session lasted $300 \mathrm{~s}$ with 51 Laser OFF and 50 Laser ON periods).

\section{Histology}

Following photo-stimulation, mice were returned to their home cage for $8 \mathrm{~h}$. Mice were then deeply anesthetized by isoflurane or intraperitoneal injection of Euthasol $(390 \mathrm{mg} / \mathrm{kg})$, and subsequent transcardial perfusion with saline followed by $10 \%$ buffered formalin (SF100-4, ThermoFisher Scientific). Brains were extracted and post-fixed in formalin for 2-4 more days after which they were placed in a $30 \%$ sucrose solution in KPBS for $1-2$ additional days. The brains were then frozen and sliced on a cryostat (Leica CM 3050S) in $40 \mu \mathrm{m}$ sections after which they were mounted and coverslipped with Vectashield Hardset mounting medium (Vector Laboratories). Slices were then imaged at 4x, 10x, and 20x on a Nikon Eclipse Ni-E 
epifluorescence microscope to verify proper placement of the fiber optic fibers above the CFA of the motor cortex.

\section{In Vivo Image Acquistion, Processing, and Analysis}

Image Acquisition in Post-Mortem Tissue After In Vivo Photo-Activation. The effect of in vivo activation on the expression of fluorescence protein was analyzed with post-mortem imaging of the histological preparations of the tissue. Fluorescent images of the prepared tissue were collected on a Nikon Exclipse Ni-E epifluorescence microscope at 10X (Plan Fluor 10x NA 0.3) and 20X (Plan Apo Lambda 20x NA 0.75) using a Sola Light Engine for excitation of fluorophores. ZsGreen was excited at 470/40 nm (peak/bandwidth) and emissions were collected at 525/50 nm, emission (495 nm dichroic mirror). eYFP was excited at 500/20 nm and emissions were collected at 535/30 nm, emission (515 nm dichroic mirror). mRuby2 was excited at 560/40 $\mathrm{nm}$ and emissions were collected at 630/60 nm, emission (585 nm dichroic mirror).

Image Processing and Analysis of post-mortem histological preparations. Automated cell counts of fluorescence labelled cells from histological preparation were performed in ImageJ using a custom written script (see Appendix 1) as described in the Methods section 


\section{Bibliography}

1. Packer, A. M., Russell, L. E., Dalgleish, H. W. P. \& Häusser, M. Simultaneous all-optical manipulation and recording of neural circuit activity with cellular resolution in vivo. Nat. Med. 12, 140-146 (2015).

2. Rickgauer, J. P., Deisseroth, K. \& Tank, D. W. Simultaneous cellular-resolution optical perturbation and imaging of place cell firing fields. Nat. Neurosci. 17, 1816-1824 (2014).

3. Szabo, V., Ventalon, C., Bradley, J. \& Emiliani, V. Patterned photoactivation with computer-generated holography and functional fluorescence imaging in freely behaving mice with a fiberscope. Neuron 84, 1157-1169 (2014).

4. Boyden, E. S., Zhang, F., Bamberg, E., Nagel, G. \& Deisseroth, K. Millisecond-timescale, genetically targeted optical control of neural activity. Nat. Neurosci. 8, 1263-1268 (2005).

5. Han, X. et al. Millisecond-timescale optical control of neural dynamics in the nonhuman primate brain. Neuron 62, 191-198 (2009).

6. Boyden, E. S. A history of optogenetics: the development of tools for controlling brain circuits with light. F1000 Biol. Rep. 3, 11 (2011).

7. Knöpfel, T. et al. Toward the second generation of optogenetic tools. J. Neurosci. 30, 14998-15004 (2010).

8. Ramirez, S., Liu, X., Lin, P. A., Suh, J. \& Tonegawa, S. Creating a false memory in the hippocampus. Science (80-. ). 341, 387-391 (2013).

9. Lee, D., Hyun, J. H., Jung, K., Hannan, P. \& Kwon, H. B. A calcium- and light-gated switch to induce gene expression in activated neurons. Nat. Biotechnol. 35, 858-863 (2017).

10. Wang, W. et al. A light- and calcium-gated transcription factor for imaging and manipulating activated neurons. Nat. Biotechnol. 35, 864-871 (2017).

11. Clapham, D. E. Calcium Signaling. Cell 131, 1047-1058 (2007).

12. Greer, P. L. \& Greenberg, M. E. From Synapse to Nucleus : Calcium-Dependent Gene Transcription in the Control of Synapse Development and Function. Neuron 59, 846-860 (2008).

13. Berridge, M. J., Lipp, P. \& Bootman, M. D. Calcium Signalling. Nat. Rev. 1, (2000).

14. Hardingham, G. E., Chawla, S., Johnson, C. M. \& Bading, H. Distinct functions of nuclear and cytoplasmic calcium in the control of gene expression. Nature vol. 385 260-265 (1997).

15. Wild, A. R. et al. Synapse-to-Nucleus Communication through NFAT Is Mediated by Ltype Ca 2+ Channel Ca 2+ Spike Propagation to the Soma. Cell Rep. 26, 3537-3550.e4 (2019).

16. Bengtson, C. P., Freitag, H. E., Weislogel, J.-M. \& Bading, H. Nuclear calcium sensors reveal that repetition of trains of synaptic stimuli boosts nuclear calcium signaling in CA1 pyramidal neurons. Biophys. J. 99, 4066-77 (2010).

17. Watanabe, S., Hong, M., Lasser-Ross, N. \& Ross, W. N. Modulation of calcium wave propagation in the dendrites and to the soma of rat hippocampal pyramidal neurons. $J$. Physiol. 575, 455-68 (2006).

18. Mellström, B. Ca2+-operated transcriptional networks: molecular mechanisms and in vivo models. Physiological 88, 421-449 (2008).

19. Deisseroth, K., Mermelstein, P. G., Xia, H. \& Tsien, R. W. Signaling from synapse to nucleus: The logic behind the mechanisms. Curr. Opin. Neurobiol. 13, 354-365 (2003). 
20. Fields, R. D., Eshete, F., Stevens, B. \& Itoh, K. Action potential-dependent regulation of gene expression: temporal specificity in ca2+, cAMP-responsive element binding proteins, and mitogen-activated protein kinase signaling. J. Neurosci. 17, 7252-7266 (1997).

21. Power, J. M. \& Sah, P. Nuclear calcium signaling evoked by cholinergic stimulation in hippocampal CA1 pyramidal neurons. J. Neurosci. 22, 3454-62 (2002).

22. Nakazawa, H. \& Murphy, T. H. Activation of nuclear calcium dynamics by synaptic stimulation in cultured cortical neurons. J. Neurochem. 73, 1075-83 (1999).

23. Yu, Y., Oberlaender, K., Bengtson, C. P. \& Bading, H. One nuclear calcium transient induced by a single burst of action potentials represents the minimum signal strength in activity-dependent transcription in hippocampal neurons. Cell Calcium 1-8 (2017) doi:10.1016/j.ceca.2017.03.003.

24. Dolmetsch, R. E., Lewis, R. S., Goodnow, C. C. \& Healy, J. I. Differential activation of transcription factors induced by $\mathrm{Ca} 2+$ response amplitude and duration. Nature 386, 855858 (1997).

25. Limback-Stokin, K. Nuclear Calcium/Calmodulin Regulates Memory Consolidation. $J$. Neurosci. 24, 10858-10867 (2004).

26. Delucinge-vivier, C. et al. Nuclear Calcium Signaling Controls Expression of a Large Gene Pool : Identification of a Gene Program for Acquired Neuroprotection Induced by Synaptic Activity. PLOS Genet. 5, 1-17 (2009).

27. Harper, S. M., Neil, L. C. \& Gardner, K. H. Structural basis of a phototropin light switch. Science (80-. ). 301, 1541-4 (2003).

28. Halavaty, A. S. \& Moffat, K. N-and C-terminal flanking regions modulate light-induced signal transduction in the LOV2 domain of the blue light sensor phototropin 1 from Avena sativa. Biochemistry 46, 14001-14009 (2007).

29. Zoltowski, B. D., Vaccaro, B. \& Crane, B. R. Mechanism-based tuning of a LOV domain photoreceptor. Nat. Chem. Biol. 5, 827-34 (2009).

30. Konold, P. E. et al. Unfolding of the C-Terminal Ja Helix in the LOV2 Photoreceptor Domain Observed by Time-Resolved Vibrational Spectroscopy. J. Phys. Chem. 7, 34723476 (2016).

31. Kennis, J. T. M. et al. The LOV2 Domain of Phototropin: A Reversible Photochromic Switch. J. Am. Chem. Soc. 126, 4512-4513 (2004).

32. Seipel, K., Georgiev, O. \& Schaffner, W. Different activation domains stimulate transcription from remote ('enhancer') and proximal ('promoter') positions. EMBO J.11, 4961-4968 (1992).

33. Cress, W. D. \& Triezenberg, S. J. Critical structural elements of the VP16 transcriptional activation domain. Science (80-. ). 251, 87-90 (1991).

34. O'Reilly, D., Hanscombe, O. \& O'Hare, P. A single serine residue at position 375 of VP16 is critical for complex assembly with Oct-1 and HCF and is a target of phosphorylation by casein kinase II. EMBO J. 16, 2420-30 (1997).

35. Lungu, O. I. et al. Designing photoswitchable peptides using the AsLOV2 domain. Chem. Biol. 19, 507-17 (2012).

36. Strickland, D., Moffat, K. \& Sosnick, T. R. Light-activated DNA binding in a designed allosteric protein. PNAS 105, 10709-10714 (2008).

37. Yang, J. \& Zhang, Y. I-TASSER server: New development for protein structure and function predictions. Nucleic Acids Res. 43, W174-W181 (2015).

38. Roy, A., Yang, J. \& Zhang, Y. COFACTOR: An accurate comparative algorithm for 
structure-based protein function annotation. Nucleic Acids Res. 40, 471-477 (2012).

39. Carrión, M., Link, W. A., Ledo, F., Mellström, B. \& Naranjo, J. R. DREAM is a Ca2+regulated transcriptional repressor. Nature 398, 80-4 (1999).

40. Bading, H. Nuclear calcium signalling in the regulation of brain function. Nat. Rev. Neurosci. 14, 593-608 (2013).

41. Mellström, B. et al. DREAM controls the on/off switch of specific activity-dependent transcription pathways. Mol. Cell. Biol. 34, 877-87 (2014).

42. Mellström, B. et al. Specific cytoarchitectureal changes in hippocampal subareas in daDREAM mice. Mol. Brain 9, 22 (2016).

43. Wu, L. J. et al. DREAM (Downstream Regulatory Element Antagonist Modulator) contributes to synaptic depression and contextual fear memory. Mol. Brain 3, 1-13 (2010).

44. Rivera-Arconada, I. et al. Dream regulates BDNF-dependent spinal sensitization. Mol. Pain 6, 95 (2010).

45. Osawa, M. et al. Calcium-regulated DNA binding and oligomerization of the neuronal calcium-sensing protein, calsenilin/DREAM/KChIP3. J. Biol. Chem. 276, 41005-41013 (2001).

46. Lusin, J. D., Vanarotti, M., Li, C., Valiveti, A. \& Ames, J. B. NMR Structure of DREAM : Implications for Ca 2 + -Dependent DNA Binding and. Biochemistry 47, 22522264 (2008).

47. Osawa, M. et al. $\mathrm{Mg} 2+$ and $\mathrm{Ca} 2+$ differentially regulate DNA binding and dimerization of DREAM. J. Biol. Chem. 280, 18008-18014 (2005).

48. Craig, T. A. et al. The metal-binding properties of DREAM. Evidence for calciummediated changes in DREAM structure. J. Biol. Chem. 277, 10955-10966 (2002).

49. Ledo, F. et al. The DREAM-DRE interaction: key nucleotides and dominant negative mutants. Biochim. Biophys. Acta 1498, 162-8 (2000).

50. Carrión, M., Mellström, B. \& Naranjo, J. R. Protein kinase A-dependent derepression of the human prodynorphin gene via differential binding to an intragenic silencer element. Mol. Cell. Biol. 18, 6921-9 (1998).

51. Tian, J. \& Andreadis, S. T. Independent and high-level dual-gene expression in adult stem-progenitor cells from a single lentiviral vector. Gene Ther. 16, 874-884 (2009).

52. Yang, J. et al. The I-TASSER suite: Protein structure and function prediction. Nat. Methods 12, 7-8 (2014).

53. Roy, A., Kucukural, A. \& Zhang, Y. I-TASSER: A unified platform for automated protein structure and function prediction. Nat. Protoc. 5, 725-738 (2010).

54. Zhang, Y. I-TASSER server for protein 3D structure prediction. BMC Bioinformatics 9, $1-8$ (2008).

55. Heckman, K. L. \& Pease, L. R. Gene splicing and mutagenesis by PCR-driven overlap extension. Nat. Protoc. 2, 924-32 (2007).

56. Zack, G. W., Rogers, W. E. \& Latt, S. A. Automatic measurement of sister chromatid exchange frequency. J. Histochem. Cytochem. 25, 741-753 (1977).

57. Tsai, W.-H. Document Image Analysis. in (eds. O’Gorman, L. \& Kasturi, R.) 44-60 (IEEE Computer Society Press, 1995). 